\title{
LA LIBERTAD SEGÚN SÖREN KIERKEGAARD
}

\section{Dr. Juan Fernando Sellés*}

Este trabajo revisa la concepción de Kierkegaard sobre la libertad humana. El filósofo danés parece acercarse a un entendimiento de la libertad como un 'trascendental personal' al afirmar su irreductibilidad al libre albedrío. No obstante, mantiene la libertad en el plano categorial, puesto que la vincula a la voluntad humana. Finalmente, se hacen algunas precisiones sobre el concepto kierkegaardiano de libertad en discusión con otros comentaristas.

Palabras clave: Kierkegaard, libertad, voluntad.

\section{FREEDOM ACCORDING TO SÖREN KIERKEGAARD}

This paper reviews Kierkegaard's conception of human freedom. The Danish philosopher seems to approach an understanding of freedom as a 'transcendental' of the human act of being in affirming its irreducibility to free will (liberum arbitrium). However, he keeps freedom within the categorial plane, since he links it to human will. Finally, some precisions are made regarding the Kierkegaardian concept of freedom in discussion with other commentators.

Keywords: Kierkegaard, freedom, will.

\footnotetext{
*Universidad de Navarra, Pamplona, España. Correo electrónico: jfselles@unav.es
} 

$-$

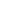




\section{Planteamiento}

PARA KieRKegaARd, el tema de la Relación entre la libertad y la necesidad es un problema que ha preocupado no solo a los filósofos, sino a todos los hombres ${ }^{1}$. En su caso, la libertad (Friheden) es el tema que más le interesó desde el comienzo ${ }^{2}$, también por oposición al sistema hegeliano en el que rige la necesidad ${ }^{3}$. Nuestro autor afirmó que, superior a la acción creadora divina, es dotar de libertad a una criatura: "la cosa más alta que se puede hacer por un ser... es rendirlo libre. Para poderlo hacer, es necesaria precisamente la omnipotencia"4. Pero en la obra del pensador danés este es, seguramente, el tema más difícil de perfilar, y el que está en la raíz tanto de la ética como de la antropología.

Kierkegaard tiene el acierto de que, desde joven, defendió la libertad humana, incluso frente a la doctrina de la predestinación luterana (siendo Lutero el autor que más le influyó), a la par que afirmó que el acto de fe es libre y que se accede a Dios por el esfuerzo moral. En su Diario se lee que "tanto San Agustín como muchos modernos han mostrado que es una ilusión concebir el libre albedrío en abstracto (liberum arbitrium); como si un hombre en todo momento de su vida se encontrase siempre provisto de esta posibilidad abstracta - de modo que en el fondo no se moviese de su sitio-, como si la libertad no fuese en todo el tiempo un estado histórico. Me parece que la cosa se puede aclarar de una manera muy simple. Pensad en una balanza de precisión: cuando ha sido usada, aún solo por 8 días, ya tiene una historia. El propietario está ahora al corriente de este hecho histórico, que la balanza tiende a propender a una parte o a otra: una historia que continúa a medida del uso que se hace. También la voluntad tiene una historia, una historia ininterrumpida, la cual puede hacer que un hombre pierda en último término la facultad de poder escoger. Con esto, sin embargo, la historia no está terminada. Porque, como San Agustín dice justamente, este estado es el castigo del pecado, y es aún pecado. El concepto de pecado se

1 "Dos cosas sobre todo, dice Leibniz al principio de la Teodicea, han puesto al hombre en dificultad: la relación entre la libertad y la necesidad y la continuidad de la materia... El primer problema ha ocupado a todos los hombres, el segundo a los filósofos". Kierkegand, Sören, Diario (1842-44) ed. de Fabro, C., Morcelliana, Brescia, vol. 3, 1980, p. 65.

2 Cfr. ibidem (1835), vol. 2, 1980, p. 35.

3 "El sistema procede con necesidad". Ibidem (1850), vol. 7, 1981, p. 191.

4 Ibidem (1846), vol. 3, 1980, p. 240. 
aferra en todo modo. No se trata de una cosa exterior, tal que el castigo sea otra cosa; no, el castigo (= la recaída), aunque sea un castigo, es aún a su vez pecado"5. Nótese que en este texto nuestro autor vincula la libertad a la voluntad. Vamos, pues, a estudiar, a continuación, si la libertad humana, según Kierkegaard, es algo más que la voluntad humana. Pero, en primer lugar, explicitemos que, según él, no se reduce al libre albedrío de esta facultad.

\section{1. ¿Se reduce la libertad humana al libre albedrío?}

La libertad de elección no es lo radical de la libertad para Kierkegaard: "en general la libertad de poder elegir es presentada como un bien muy extraordinario. Ahora bien, aunque lo es, sin embargo eso depende de cuanto durará. Porque usualmente se engaña quien imagina que es un bien porque dura toda la vida. ¡Oh!, cuánta verdad y experiencia hay en eso que Agustín dice de la verdadera libertad (diversa de la libertad de elección): el sentimiento más fuerte lo tiene el hombre cuando, con una plena decisión, imprime a su acción aquella interior necesidad que excluya el pensamiento de otra posibilidad. Entonces el 'tormento' de la libertad de elección ha terminado"6.

Según sus estudiosos, Kierkegaard entiende la libertad de doble modo: como libertas y como libre albedrío (frie Ville). La primera es la ordenación al fin, la cual se perdió con el pecado de origen; la segunda es la capacidad de elegir; que, en rigor-según el pensador danés- es una quimera ${ }^{7}$. La clave de la vida es ganar con sufrimiento la libertas, la cual no se alcanza sin la ayuda divina ${ }^{8}$. Se trata, entonces, de dar un salto: en la medida en que uno se dirige al fin, abandona paulatinamente el libre albedrío, y su libertad se convierte en necesidad.

En su Diario el escritor de Copenhague habla de la elección como de una determinación de la libertad: “¿Se podría exponer con precisión mayor que la libertad de elección es sólo una determinación formal de la libertad? ¿Y que propiamente la acentuación de la libertad de elección como tal es la pérdida de la libertad? El contenido de la libertad es decisivo para la libertad hasta tal punto que la verdad de la libertad de elección está a punto de admitir que aquí no debe haber elección, aunque sea una elección. Esto es ser 'espíritu'. Pero propiamente porque los hombres están lejos de serlo, la libertad les da tanto fastidio, en cuanto ellos quedan siempre aferrados a la libertad de elección... La libertad está en el fondo solo cerca de esta condición; esto es en el mismo momento, en el mismo segundo que ella es (libertad de elección), se acelera incondicionadamente, en cuanto que

\footnotetext{
Ibidem (1851-52), vol. 8, 1981, p. 237.

Ibidem (1851), vol. 9, 1982, p. 9.

"Que un 'libre albedrío' puro y simple sea una quimera, se ve en mejor que en nada en la dificultad del prolongado esfuerzo que es necesario para remover solo un hábito, aún después de haber hecho un serio propósito”. Ibidem (1849), vol. 6, 1981, p. 19.

8 Cfr. Viallaneix, Nelly, "Le liberté chez S. Kierkegaard: écoute ton Libérateur", Les Cahiers de Philosophie, 8-9, 1989, pp. 23-34.
} 
incondicionadamente se ata a sí misma por vía de la elección de la decisión, de aquella elección que tiene por principio: que no puede ser cuestión de elección... la cosa enorme concedida al hombre es la elección, la libertad. Si tú la quieres salvar o conservar, no hay más que una vía: aquella de, en el mismo segundo, absolutamente en plena decisión, rendirla a Dios y a ti en ella. Si te tienta la vanidad de guardar eso que te ha estado concedido, si tú sucumbes a la tentación y guardas con ansia egoísta la libertad de elección, perderás la libertad... Tú dices: yo tengo la libertad de elección, pero tú no has escogido todavía a Dios... Tú suspiras que has perdido la libertad de elección"9.

Para Binetti "la cuestión de la libertad protagoniza el pensamiento de Sören A. Kierkegaard y establece el fundamento sobre el cual descansa su entero edificio existencial"10. La describe como el "itinerarium in Deum"11. Para esta autora "la existencia como libertad en acto podría ser el título del pensamiento kierkegaardiano, cuyo subtítulo es... la identidad ético-existencial del cómo y del qué"12. También para Torralba Roselló "la libertad constituye un tema axial en el corpus kierkegaardiano ${ }^{13}$. Para Barreiro, según Kierkegaard, "mientras el hombre no actúa por la elección del Absoluto, no se puede hablar de libertad" ${ }^{\prime \prime}$. Pero elegir es propio del libre albedrío. Fabro, en cambio, indica que la libertad que describe el pensador danés es radical, constitutiva, fontanal en el hombre, y se distingue de las libertades regionales, es decir, de la aplicación de esa libertad a diversas realidades. Es una libertad que se $e s$, no que se tiene ${ }^{15}$. El pensador italiano la hace, por tanto, equivalente al acto de ser del hombre y la llama arché. Para él, la libertad, según Kierkegaard, es una energía originaria, una capacidad activa, una apertura ilimitada ${ }^{16}$.

9 Kierkegand, S., Diario (1849-50), op. cit., vol. 6, 1981, pp. 83-84.

10 Binetti, María José, "La posibilidad necesaria de la libertad. Un análisis del pensamiento de Kierkegaard,"Cuadernos de Anuario Filosófico, Serie Universitaria, n ${ }^{\circ}$ 177, Servicio de Publicaciones de la Universidad de Navarra, Pamplona, 2005, p. 7. También FrAnCO BARRIO es de este parecer: "para Kierkegaard, la libertad constituye la esencia del hombre". Franco BARrio, Jaime, Kierkegaard frente al hegelianismo, Universidad de Valladolid, Valladolid, 1996, p. 80.

11 Binetti, María José, El itinerario de la libertad. Un estudio basado en el Diario de Sören Kierkegaard según la interpretación de Cornelio Fabro, Ciafic, Buenos Aires, 2003, p. 243.

12 Ibidem, p. 200.

13 Torralba Roselló, Francesc, Poética de la libertad. Lectura de Kierkegaard, Caparrós Editores, Madrid, 1998, p. 37. Más adelante añade: "Para Kierkegaard, la afirmación de la libertad constituye el centro de gravedad de su discurso filosófico-teológico". Ibidem, p. 76.

14 Barreiro, José Luis, "Sören Kierkegaard y las fases de la personalidad", Compostellanum, 15 (1970), p. 417.

15 Cfr. Fabro, Cornelio, L'essere e la libertà, pro manuscripto, Perugia, Año Académico 1967-1968, pp. 68-69.

16 Cfr. Fabro, Cornelio, Dall'essere all existente, Morcelliana, Brescia, 1957, p. 255. Del Diario de Sören, Fabro saca estos puntos conclusivos respecto de la libertad: a) El fundamento metafísico de la libertad es la elección de Dios. b) El fundamento existencial de la libertad es la elección de Dios. c) El fundamento objetivo de la libertad es la constricción de Dios. d) El objetivo esencial de la libertad es devenir yo (Selvet). e) El supremo objetivo de la libertad es devenir cristiano. No obstante, estas conclusiones esconden dos tesis que no parecen compatibles, a saber, que en unas de ellas se considera que la libertad es una energía nativa, mientras que en otras se declara que la libertad radica en la elección de Dios para devenir un yo y llegar a ser cristiano. Ahora bien, la elección es un acto adquirido de la voluntad. Por tanto, en rigor, hay disparidad entre dotación natural y adquisición. En efecto, para Fabro, el ser es la libertad (libertad nativa); a su vez, la libertad se adquiere en el obrar (libertad adquirida). ¿Con qué carta quedarse? ¿Acaso se pueden reducir a la identidad ambos planos? ¿Cómo distinguirlas y compatibilizarlas? Cfr. sobre este tema: Pizzuti, Giuseppe Mario, Il filosofo dell'actus essendi. La progressione teoretica dell'itinerario filosofico di Cornelio Fabro tra Tommaso d'Aquino e Sören Kierkegaard, Edizioni Scientifiche Italiane, Napoli, 2011. 


\section{2. ¿Es la libertad, según el pensador danés, un ‘trascendental personal’?}

Alguna de las descripciones precedentes puede dar la impresión de que Kierkegaard concibe la libertad como un trascendental personal, es decir, como una dimensión o perfección pura del acto de ser personal o intimidad humana. En efecto, si la libertad es la que -con la ayuda divina- permite dar el 'salto', será lo más activo y noble en el ser humano. Pero ¿esto significa que Kierkegaard la concibe como un trascendental personal?, es decir, como un radical nativo del sujeto, una dimensión del núcleo personal humano que dice relación constitutiva al ser divino. $\mathrm{O}$, por el contrario, ¿la concibe más bien como una realidad humana de orden categorial, o sea, perteneciente al ámbito del tener humano?, ¿tal vez a la voluntad? Se puede sostener que su concepción de la libertad es de orden categorial por varios motivos:

1. Uno, porque Kierkegaard vincula la libertad a la voluntad ${ }^{17}$ (incluso a la pasión), la cual es de orden predicamental (la persona, cada quien, no es su voluntad; tampoco su pasión, sino que tiene una facultad a la que llamamos voluntad, o unas redundancias afectivas a las que llamamos pasiones). Incluso asimilándola a la voluntas ut natura de la que hablaba Tomás de Aquino (como hace Binetti) no se puede sostener que tal voluntad sea de orden trascendental, porque tal expresión describe a dicha potencia en su estado nativo en la medida en que dice una relación al bien real que la trasciende, a saber, al fin último. Pero obviamente la voluntad no conforma el acto de ser personal humano, porque ninguna persona se reduce a su voluntad, sino que puede con ella. La voluntad es algo que tiene, no algo que es. Lo trascendental en la voluntad es solo su relación originaria respecto del bien último, por así decir, su diseño originario referido a aquello de que carece y sin lo cual no puede llegar a culminar.

2. Otro, por su neta influencia luterana, pues el Reformador protestante concibió la libertad -de modo similar a la tradición filosófica de los siglos precedentes- en el contexto del libre albedrio, que es de orden categorial. Con todo, el filósofo danés, que sabe que Lutero no es claro en el tema de lo voluntario ${ }^{18}$, habla de 'elegirse a sí mismo' y de 'elegir a Dios', y es manifiesto que estos temas no caen bajo el libre albedrío, puesto que no son 'medios'. Por tanto, esa 'elección' peculiar de la que habla Kierkegaard no parece reducirse al acto de la voluntad así llamado. No obstante, la índole de tales 'elecciones' no está bien perfilada, y no se pueden hacer equivalentes, sin más matices, a la 'libertad trascendental'.

17 "Sólo la libertad puede salir de la duda en la cual he entrado con la libertad... Pero si debo liberarme de la duda con la libertad, también debo haber entrado con la libertad (con un acto de voluntad)". KierkegaArd, S., Diario (1842-43), op. cit., vol. 3, 1980, p. 108. 
3. Otro, por el innegable influjo de Kant en Kierkegaard, pues el filósofo de Königsberg ciñó la libertad en exclusiva a la voluntad espontánea. Lo que buscó Sören -como el pensador alemán- fue erradicar la relación de dependencia de la voluntad respecto de los objetos racionales y, asimismo, de las realidades externas, los bienes reales. Recuérdese que Kant concibe la voluntad como 'pura' y 'santa' por naturaleza, sin que se adapte a bienes externos. Pero si el danés describe a la libertad como 'querer libre', parece claro que la circunscribe a la voluntad.

4. Que la libertad tal como la describe Kierkegaard es de orden categorial se puede comprobar en sus escritos porque en ellos trata de la libertad en un contexto ético. Téngase en cuenta que la ética no es trascendental, pues estudia el obrar humano, no el ser del hombre. A ello se puede objetar que los límites entre ética y antropología no están perfilados en el pensamiento del danés, lo cual es verdad. En efecto, no lo pueden estar, porque lo que más pesa en su antropología no es el ser, sino el hacerse, el devenir, y este tema es propio de la ética.

5. No puede considerarse que la concepción kierkegaardiana de la libertad sea de orden trascendental, porque la libertad trascendental es la apertura nativa del ser humano al ser divino, en rigor, la vinculación de la persona humana a Dios, mientras que Kierkegaard -por neto influjo de Kant y de Lutero, y en deuda de ambos con Ockham- la entiende como 'independencia extrínseca'. Lo mismo lleva a cabo en su concepción ética: no puede vincular la voluntad al bien porque -según la mentalidad kantiana- eso indicaría interés.

Problema distinto es dilucidar si la libertad, tal como la concibe Fabro, es o no trascendental. Pero esta cuestión, desde luego interesante, excede el marco de este estudio ${ }^{19}$. Con todo, cabe decir de paso que lo positivo de la concepción fabriana de la libertad radica en haber reparado en el sublime valor de ella; lo negativo o reductivo, en cambio, es haberla restringido a la voluntad, hecho por el cual admite, frente a la tesis clásica (por ejemplo, de Tomás de Aquino), que la voluntad es superior a la inteligencia ${ }^{20}$. Y es precisamente en este punto en el que el pensador de Copenhague ha influido más en Fabro que el de Aquino. Por eso Fabro intentó hacer equivalentes la voluntad y la subjetividad ${ }^{21}$.

19 En unos pasajes de su obra Fabro da a entender que la libertad radica en el acto de ser; en otros la ciñe a la voluntas ut natura. Pero ambas tesis no son compatibles. Cfr. al respecto: Acerbi, Ariberto, y Romera, Luis, "El pensamiento de Fabro acerca de la libertad" en La antropología de Cornelio Fabro, Anuario Filosófico, XXXIX/1 (2006), pp. 101-131; ZızI, Paolo, Ontologia della libertà (Tra Kierkegaard-Heidegger-Fabro), Unidata, Sassari,1987.

20 Cfr. al respecto: Fabro, Cornelio, "Freedom and existence in contemporary philosophy and St. Thomas", The Thomist, XXXVIII-3 (1974), pp. 521-556; "El primado existencial de la libertad”, Scripta Theologica, XIII, 2-3 (1981), pp. 323-337; “Atto esistenziale e impegno della libertà”, Divus Thomas, 1983, LXXXVI/2-3, (1983), pp. 125-161; Riflessioni sulla libertà, Segni (Rm), 2004; La preghiera nel pensiero moderno, Roma, 1983; "Libertà teologica, antropologica ed esistenziale”, en SÁnchez-Sorondo, Marcello (ed.), Atti del Colloquio Internazionale di Etica, Città del Vaticano, 1991, pp. 15-30. Entre los inéditos se encuentra el siguiente texto correspondiente a un curso en la universidad de Perugia: Essere e libertà, Perugia, 1967-68, pro manuscripto.

21 "La voluntad será, por tanto, la subjetividad constitutiva y constituyente última del yo, y el dinamismo supremo de la persona". BinetTi, M. J., El itinerario..., op. cit., p. 183. 


\section{3. ¿Cuál es la índole de la libertad según Kierkegaard?}

Para Binetti -una de las personas que más ha investigado este tema en Sören- la libertad kierkegaardiana, esa libertad originaria de la que hablaba Fabro, es "posibilidad para la posibilidad"22, nada aún como realidad. También para Torralba Roselló, para quien "en el plano antropológico, la noción de ser se puede traducir como posibilidad, mientras que la de esencia se puede comprender bajo la categoría de necesidad"23, la libertad equivale a la posibilidad. Sin embargo, Kierkegaard escribió que "la libertad nunca es una posibilidad, sino que es una realidad desde el mismo momento en que hay libertad" 24 . Lo posible para la libertad es el futuro ${ }^{25}$.

Kierkegaard escribió que "las bases de la decisión son la ética y la libertad"26. Para él no se trata de elegir el bien o el mal, o entre el bien y el mal, sino de elegir querer, o sea, la libertad no es elegir solo entre esto o lo otro, sino elegir el acto de elegir ${ }^{27}$, pues el acto de querer o la abstención también se eligen. Con todo, aun así entendida, esta libertad es de orden categorial y está fundamentalmente encuadrada en la voluntad. Sören habla de elegir; de que elegir "es lo serio de la vida" ${ }^{28}$, pues con la elección el hombre se juega la gloria ${ }^{29}$; también habla de decidir. Jolivet resumía esta tesis kierkegaardiana diciendo que "lo propio de la existencia es elegir" 30 . Pero, conviene insistir: esta faceta de la libertad está vinculada a la voluntad, no a la 'libertad trascendental', o sea, al acto de ser personal visto como libertad, como la energía del espíritu.

La libertad, según nuestro autor, puede abrirse a lo superior (en rigor, a Dios) o a lo inferior. Cuando se abre a lo inferior (en definitiva, a la nada) aparece la angustia, que es fruto de la culpa. En esa tesitura se pierde la libertad. En ambos casos entiende la libertad como elección, la cual es manifestativa, no lo radical en el hombre ${ }^{31}$. Kierkegaard no

22 BinetTi, M. J., El itinerario..., op. cit., p. 102. En otro lugar esta autora escribe que Sören considera la libertad como "posibilidad infinita y necesaria de poder ideal, dialéctico, intensivo y relacional" (BinetTI, M. J., "La posibilidad...", op. cit., p. 15), es decir, como una posibilidad espiritual infinita que, en el fondo, coincide con su propia necesidad, y que es relacional respecto de Dios.

23 Torralba Roselló, F., Poética..., op. cit., p. 63. Por el contrario, Maceiras Fafian interpreta la esencia como posibilidad. Cfr. MACEIRAs, Manuel, Schopenhauer y Kierkegaard: sentimiento y pasión, Cincel, Madrid, 1985, p. 138.

24 KierkegaArd, Sören, El concepto de angustia, Guadarrama, Madrid, 1965, p. 59.

25 "Lo posible corresponde por completo al futuro. Lo posible es para la libertad lo futuro, y lo futuro es para el tiempo lo posible". Ibidem, p. 173.

26 Kierkegaard, Sören, Etapas en el camino de la vida, ed. de Juana Castro, Buenos Aires, S. Rueda, 1952, p. 116.

27 'Lo que se hace patente a través de mi 'o... o...' es lo ético. No por ello se trata todavía de elegir alguna cosa, no se trata de la realidad de lo elegido, sino de la realidad del elegir”. KiERKEGAARD, Sören, O lo uno o lo otro. Un fragmento de vida, vol. II, Trotta, Madrid, 1997, p. 164.

28 KierkegaArd, Sören, “L'évangile des soufrances", Discours édifiants, en Euvres Complètes, Éd. de L'Orante, Paris, vol. 13, p. 244.

29 KierkegaArd, Sören, "Nous en venons à la gloire du choix qu'il est accordé à l' homme de faire". "Les lis des champs et les oiseaux du ciel", Discours édifiants, en Euvres Complètes, ed. cit., vol. 13, p. 197.

30 Jolivet, Régis, Las doctrinas existencialistas, Gredos, Madrid, 4 ed., 1976, p. 51. 
comprende la libertad como opuesta a la necesidad, porque no la estudia desde el punto de vista metafísico, sino a la culpa ${ }^{32}$, porque la entiende desde el plano de la ética. Con la culpa se pierde la libertad ${ }^{33}$. El fruto de esta pérdida se experimenta como angustia ${ }^{34}$, sentimiento negativo del espíritu (bien descrito en una de las obras más célebres del pensador danés: El concepto de angustia). Inmerso en la culpa el hombre puede cerrarse en sí mismo $^{35}$, sin querer salir de esa situación y sin pedir ayuda a nadie. En cambio, si se abre, cabe salvación: "la apertura es aquí el bien; puesto que la apertura es la primera expresión de la salvación" 36 . El punto positivo de esta descripción radica en concebir la libertad como apertura.

La libertad puede perderse en diferentes planos. Kierkegaard señala que existe una pérdida somático-psíquica de ella, por un lado, y una pérdida pneumática, por otro. La segunda privación es más grave que la primera, porque tal libertad es más intrínseca al sujeto. Como se puede apreciar, nuestro autor distingue diversos niveles humanos de libertad. Pero esto no significa que, según él, el hombre sea una libertad nativa ${ }^{37}$, cada quien, una libertad distinta -libertad personal que luego canalice en las diversas mani-festaciones humanas-, pues afirma que "la decisión es el verdadero comienzo de la libertad"38 y la decisión es claramente un acto adquirido.

Que Kierkegaard entiende la libertad desde el punto de vista ético es neto, porque sin ella la tarea de perfeccionamiento humano a lo largo de la existencia en que consiste la ética es imposible: "todo hombre se desarrolla con libertad.... Un hombre no se crea a sí mismo de la nada... él mismo en su concreción es una tarea" 39 . A su vez, la ética es la base para la decisión religiosa: "la decisión es una concepción religiosa de la vida, construida sobre datos éticos" ${ }^{\$ 4}$. El paso de la ética a la religión radica precisamente en la decisión: "la decisión no es la fuerza del hombre, ni su coraje, ni su habilidad... sino que es un punto de

31 Frente a esta tesis Fabro defiende que la libertad para Kierkegaard es el núcleo del ser humano. Cfr. FABro, Cornelio, Tra Kierkegaard e Marx, en Opere Complete, vol. 9, Logos, Roma, 1978. En el cap. V añade: "Para Kierkegaard la libertad es sobre todo posibilidad de escoger la verdadera elección, de escoger eso que únicamente se debe escoger, de escoger el Absoluto y así obtener la libertad de la segunda vuelta, la libertad como acto". Ibidem, p. 99. En cambio, para GARCía AMILBuRu, "la libertad es principalmente para Kierkegaard capacidad de elección”. García Amilburu, María, La existencia en Kierkegaard, Eunsa, Pamplona, 1992, p. 180.

32 "Interpretando así la libertad, ésta se opondría a la necesidad, lo cual demuestra que se ha concebido la libertad dentro de una categoría puramente mental. No, lo opuesto de la libertad es la culpa”. KierKegaARD, S., El concepto..., op. cit., p. 200.

33 "La libertad ha quedado establecida como no-libertad, pues se ha perdido la libertad". Ibidem, p. 225.

34 "La relación de la libertad con la culpa es la angustia". Ibidem, p. 201.

35 "La libertad es siempre comunicativa... la no-libertad, en cambio, se encierra cada vez más dentro de sí misma y no desea tener ninguna comunicación... El ensimismamiento es cabalmente mutismo. El lenguaje y la palabra son, en cambio, lo salvador". Ibidem, p. 227.

36 Ibidem, p. 232.

37 Para Kierkegaard, "el hombre no nace libre, pero tampoco nace esclavo. Ya desde el principio de su vida, tiene la posibilidad de ser libre". Torralba Roselló, F., Poética..., op. cit., p. 82.

38 KierkegaArd, S., Etapas., op. cit., p. 168.

39 Kierkegaard, S., O lo uno..., op. cit., vol. II, p. 291.

40 Kierkegatrd, S., "Palabras sobre el matrimonio", en Tres discursos sobre circunstancias supuestas, Trotta, Madrid, 2010, p. 169. 
partida religioso" ${ }^{\prime 4}$. Esta decisión -según el pensador de Copenhague-sobrepasa el conocimiento; por eso declara que se ejercita en temas que sobrepasan a la reflexión, como son el amor $^{42}$ y la fe (téngase en cuenta que esta última, según el escritor danés, versa sobre lo absurdo). Como se puede apreciar, Kierkegaard concibe a la voluntad como hegemónica sobre la razón.

Kierkegaard -como buen luterano- basa su fe en la sola Scriptura ${ }^{43}$, y busca que los textos estén aprobados canónicamente, pero es consciente de que los textos no dan la fe sobrenatural, sino que esta procede de Dios. Lo que quiere indicar es que en este te-rreno no se trata solo de asuntos racionales 'objetivos', filológicos, históricos, etc., sino, ante todo, de asuntos 'subjetivos': fe, decisión, las cuales son internas: “toda decisión, toda decisión esencial, reside en la subjetividad" "44. Y así, el cristianismo es -según él- un asunto de decisión: "si ser cristiano es la dificultad, la decisión absoluta, entonces la única introducción posible es la que repele y justamente por repulsión apunta a que se trata de la decisión absoluta" ${ }^{95}$.

No cabe ética sin libertad; no cabe cristianismo sin libertad. Pero ¿qué es la libertad para Kierkegaard? Por una parte, y de acuerdo con la ética, la libertad es la dimensión humana por medio de la cual individualizamos nuestra historia, particularizamos nuestra existencia mediante las decisiones finitas, es decir, lo que favorece la realización de las diversas concreciones de la existencia humana (asunto que no dejará caer en saco roto el existencialismo posterior). Por otra parte, y de acuerdo con el cristianismo, la libertad es la que se elige a Dios o reniega de él.

De acuerdo con lo que precede, en ambos casos se trata de una libertad dialéctica, de decir, de 'alternativa' (aut-aut). Por tanto, la libertad del sujeto, según Kierkegaard, no se puede entender como una nativa apertura a la realidad irrestricta, sobre todo, a la realidad divina, esto es, no se puede entender como 'libertad trascendental', sino como una capacidad de escoger o no escoger, que se puede inclinar, por una parte, a cosas externas y, por otra, a Dios.

41 Ibidem, p. 170.

42 Cfr. ibidem, p. 171.

43 Kierkegaard, S., "El cristianismo es el Evangelio", Diario (1851), op. cit., vol. 9, 1981, p. 22.

44 Kierkegand, Sören, Post-scriptum definitivo y no científico a las 'Migajas filosóficas' (1846), Sígueme, Salamanca, 2010, p. 44.

45 Ibidem, 377. Cfr. asimismo: ibidem, p. 33. 


\section{A modo de conclusión}

Los intérpretes de Kierkegaard vinculan la libertad, bien con la posibilidad, bien con la necesidad. Para unos, ser libre sería elegir de entre posibilidades; para otros en cambio, sería escoger lo mejor, para que la libertad deviniese necesaria. Repárese, sin embargo, que tanto la posibilidad como la necesidad son nociones lógicas (de filosofía modal, en concreto), no referidas a la realidad. Por tanto, hay que verlas como nociones ajenas a las preferencias del autor danés, porque ambas, por pertenecer a la línea especulativa del racionalismo-idealismo, están muy lejos de tener que ver con la explícita hegemonía de la voluntad defendida por Kierkegaard. De modo que, en su caso, es pertinente vincular la libertad a la voluntad, no a la razón. No parece, pues, que la libertad, según nuestro filósofo, sea posibilidad o necesidad, sino decisión, que no es ni una cosa ni otra.

Tampoco la fe tiene que ver, en el pensamiento de Sören Kierkegaard, con la posibilidad o con la necesidad, porque es un asunto asimismo de la voluntad. Por eso es sin contenido; más aún, como la fe de Kant, está al margen de la razón, y como la de Lutero (al igual que la de Ockham), es la del credo quia absurdum. Asimismo, la culpa no tiene que ver ni con la posibilidad ni con la necesidad racional, sino con la voluntad. Y es claro que, en Kierkegaard, sí tienen relación entre sí la libertad, la voluntad, la fe y la culpa. Las tres primeras guardan una relación positiva entre sí; la última es contraria, negativa, respecto de las precedentes.*

\section{Bibliografía}

Acerbi, Ariberto, y Romera, Luis, 'El pensamiento de Fabro acerca de la libertad' en "La antropología de Cornelio Fabro”, Anuario Filosófico, XXXIX/1 (2006), pp. 101-131.

BArreiro, José Luis, "Sören Kierkegaard y las fases de la personalidad", Compostellanum, 15 (1970), p. 417.

Binetti, María José, "La posibilidad necesaria de la libertad. Un análisis del pensamiento de Kierkegaard”, Cuadernos de Anuario Filosófico, Serie Universitaria, no 177, Servicio de Publicaciones de la Universidad de Navarra, Pamplona, 2005, p. 7.

, El itinerario de la libertad. Un estudio basado en el Diario de Sören Kierkegaard según la interpretación de Cornelio Fabro, Ciafic, Buenos Aires, 2003.

*Artículo recibido: 4 de mayo de 2012. Aceptado: 13 de julio de 2012. 
FABro, Cornelio, "Atto esistenziale e impegno della libertà", Divus Thomas, 1983, LXXXVI/2-3, (1983), pp. 125-161.

--------------, Dall'essere all existente, Morcelliana, Brescia, 1957.

-, “El primado existencial de la libertad”, Scripta Theologica, XIII, 2-3 (1981), pp. 323-337.

-, La preghiera nel pensiero moderno, Roma, 1983.

, L'essere e la libertà, pro manuscripto, Perugia, Año Académico 1967-1968.

-------------, “Libertà teologica, antropologica ed esistenziale”, en SÁnCHEZ-Sorondo, Marcello (ed.), Atti del Colloquio Internazionale di Etica, Città del Vaticano, 1991, pp. $15-30$.

------------, "Freedom and existence in contemporary philosophy and St. Thomas", The Thomist, XXXVIII-3 (1974), pp. 521-556.

--------------, Riflessioni sulla libertà, Segni, Roma, 2004.

-, Tra Kierkegaard e Marx, en Opere Complete, vol. 9, Logos, Roma, 1978.

Franco Barrio, Jaime, Kierkegaard frente al Hegelianismo, Universidad de Valladolid, Valladolid, 1996.

García Amilburu, María, La existencia en Kierkegaard, Eunsa, Pamplona, 1992.

Jolivet, RÉGIS, Las doctrinas existencialistas, Gredos, Madrid, 4a ed., 1976.

KierkegaArd, Sören, Diario (1835), ed. de Fabro, C., Morcelliana, Brescia, vol. 2, 1980.

------------------, Diario (1842-44), ed. cit., vol. 3, 1980.

-, Diario (1846), ed. cit., vol. 3, 1980.

-, Diario (1849), ed. cit., vol. 6, 1981.

-, Diario (1849-50), ed. cit., vol. 6, 1981.

-, Diario (1850), ed. cit., vol. 7, 1981. 
, Diario (1851-52), ed. cit., vol. 8, 1981.

-, Diario (1851), ed. cit., vol. 9, 1982.

-, El concepto de angustia, Guadarrama, Madrid, 1965.

-, Etapas en el camino de la vida, ed. de Juana Castro, S. Rueda, Buenos Aires, 1952.

-----------------, "L'évangile des soufrances", Discours édifiants, en Euvres Complètes, Éd. de L'Orante, Paris, vol. 13.

-------------------, O lo uno o lo otro. Un fragmento de vida, vol. II, Trotta, Madrid, 1997. , "Palabras sobre el matrimonio", en Tres discursos sobre circunstancias supuestas, Trotta, Madrid, 2010.

Post-scriptum definitivo y no científico a las 'Migajas filosóficas' (1846), Sígueme, Salamanca, 2010.

Maceiras, Manuel, Schopenhauer y Kierkegaard: sentimiento y pasión, Cincel, Madrid, 1985.

Pizzuti, Giuseppe Mario, Il filosofo dell'actus essendi. La progressione teoretica dell'itinerario filosofico di Cornelio Fabro tra Tommaso d'Aquino e Sören Kierkegaard, Edizioni Scientifiche Italiane, Napoli, 2011.

Torralba Roselló, Francesc, Poética de la libertad. Lectura de Kierkegaard, Caparrós Editores, Madrid, 1998.

Viallaneix, Nelly, "Le liberté chez Kierkegaard: écoute ton Libérateur", Les Cahiers de Philosophie, 8-9, 1989, pp. 23-34.

Zizi, Paolo, Ontologia della libertà (Tra Kierkegaard-Heidegger-Fabro), Unidata, Sassari, 1987. 